\title{
Action awaits on antimicrobial misuse
}

- Cite as: CMAJ 2017 October 2;189:E1246-7. doi: 10.1503/cmaj.1095501

Posted on cmajnews.com on Sept. 13, 2017.

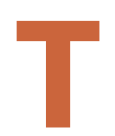

hree years after the Canadian government released its federal framework for action on antimicrobial drug use, the Public Health Agency of Canada (PHAC) has released a pan-Canadian framework for action on the same issue.

Based on input from three committees of scientists, industry officials, and federal, provincial and territorial officials, PHAC's framework - the first national consensus document ever crafted by the federal government on the issue - states that drug misuse on farms and in clinical settings "is a cause for urgent action," that surveillance is fragmented, and that leadership has been "spare and inconsistent."

But beyond these admissions, the framework contributes little that is new, said Bob Hancock, director of the Centre for Microbial Diseases and Immunity Research at the University of British Columbia. "I'm really disappointed," said Hancock, who served on one of the committees. "This document lacks novelty, and it lacks an actionable plan."

Dr. Theresa Tam, Canada's Chief Public Health Officer, does not contest that, although the framework proposes 13 "opportunities for action," it lacks an actionable plan. Tam said the government's strategy is to tighten veterinary control over some types of drug use on farms while building a national consensus for bolder steps.

Under a process that could take years, Tam said, PHAC can start to convert its action framework into an action plan. Once the action plan is drafted, the framework proposes that PHAC may then define government roles and lay out the details of concrete deliverables, timelines, measurable outcomes, priorities and allow for the tracking of progress.

Meanwhile, no new money has been allocated by the federal government to

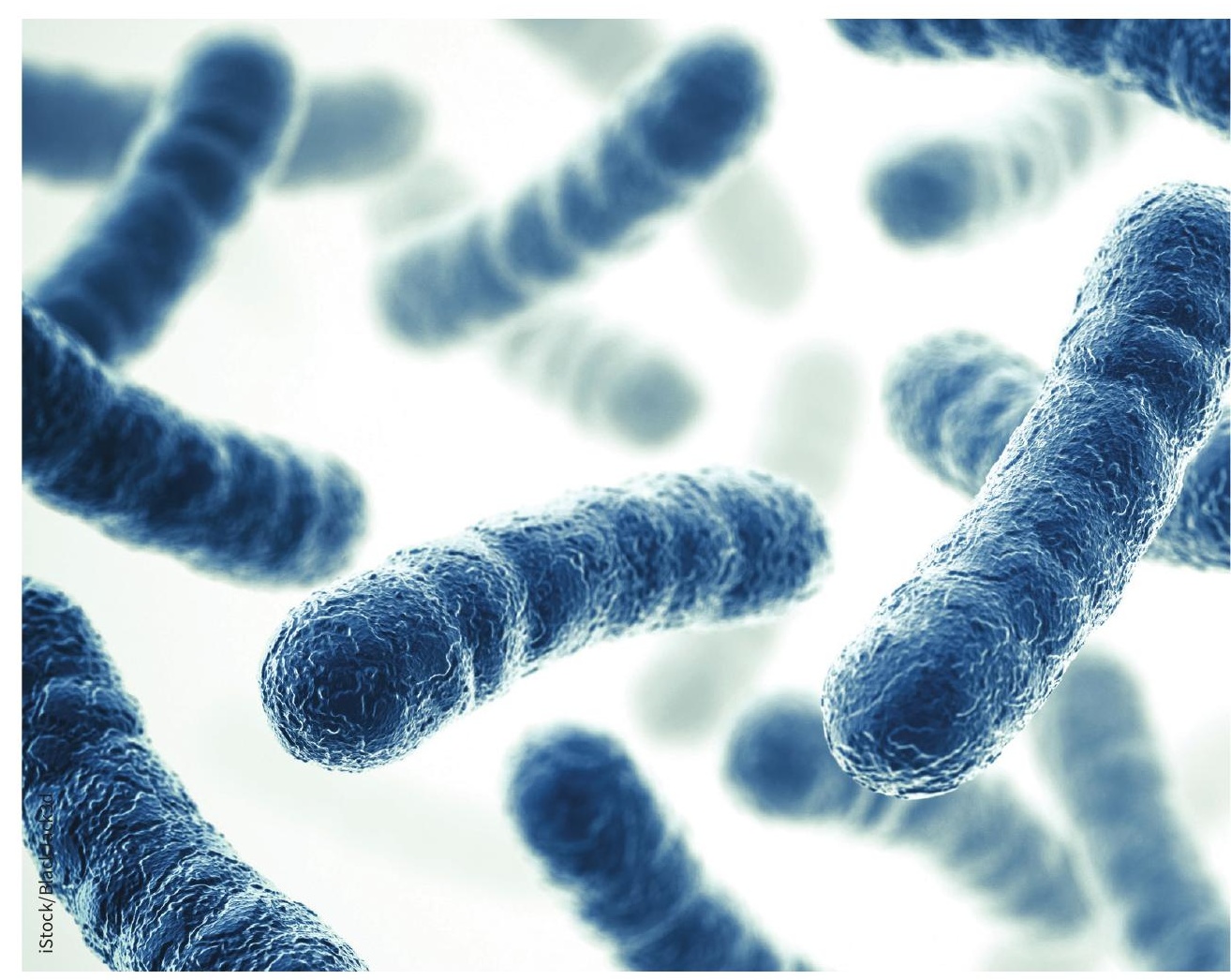

Canada has a new framework for action on antimicrobial misuse but still no actionable plan.

expedite this process, Tam confirmed. "Agencies such as ours can only do so much," she lamented.

According to Hancock, "Canada does not deserve yet more vagueness on this issue, and the lack of federal investment is severely concerning."

Describing antimicrobial resistance as "a massive public health problem," Hancock warned that "something like $20 \%$ of all deaths are sepsis-related. This utterly dwarfs the SARS crisis, swine flu, HIV, hepatitis - important as all of these problems certainly are."

A 2016 federal surveillance report indicated that Hancock's worries about antimicrobial misuse and the growing threat of drug-resistant pathogens are justified.
The report noted that about $82 \%$ of antimicrobials important to human medicine sold in Canada in 2014 were consumed by animals, and that Canada's consumption of antimicrobial drugs that year was 44 times that of Norway's.

There are critical gaps in key pathogen surveillance, the report stated. There are no data from rural and northern areas, First Nations and Inuit communities, and limited information from outpatient clinics, long-term care facilities and the offices of physicians and dentists.

Though there was progress in reducing the usage of cephalosporin antibiotics by $60 \%$ on farms between 2011 and 2014, the report showed that farmers' use of fluoro- 
quinolones - which like cephalosporins are classified as "very high importance to human medicine" - has increased $40 \%$ since 2010.

More than a third of gonorrhea cases in Canada are now resistant to ciprofloxacin, erythromycin and tetracycline, the report noted.
University of Calgary medical microbiologist Dr. Johann Pitout credits PHAC's framework for acknowledging the need for better drug use data and drug resistance data from long-term care facilities, even if it doesn't go so far as identifying it as an "opportunity for action."

At the BC Centre for Disease Control, medical epidemiologist Dr. David Patrick also credits PHAC for setting the stage for the development of a national action plan. "At this stage, though, we're not seeing PHAC move ahead with funded action" he added.

Paul Webster, Toronto, Ont. 